\title{
EHMTI-0393. Abnormal ictal large-scale network connectivity in migraine without aura: a resting- state functional connectivity study
}

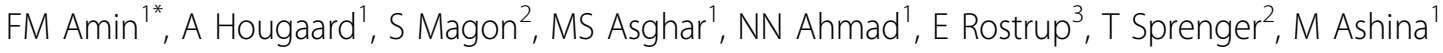 \\ From 4th European Headache and Migraine Trust International Congress: EHMTIC 2014 \\ Copenhagen, Denmark. 18-21 September 2014
}

\section{Introduction}

Alterations in cerebral resting-state functional connectivity (RSFC) have been reported outside of migraine attacks. To date, no studies studied possible changes in RSFC during migraine attacks.

\section{Aims}

To investigate resting-state functional connectivity in salience (SN), sensorimotor (SMN) and default mode networks (DMN) during the early phase of pituitary adenylate cyclase-activating polypeptide-38 (PACAP38)-induced migraine attacks.

\section{Methods}

In a double-blind randomized study, 24 female migraine patients without aura received intravenous PACAP38 or vasoactive intestinal polypeptide (VIP) for $20 \mathrm{~min}$. Both peptides are closely related and cause vasodilatation, but only PACAP38 induces migraine attacks. VIP was therefore used as an active placebo. Functional MRI was recorded before and during PACAP38-induced attacks $(\mathrm{n}=16)$ and before and after VIP infusion $(\mathrm{n}=15)$. Data were analyzed by SPM8 and the REST toolbox for Matlab in a seed-based fashion.

\section{Results}

During PACAP38-induced attacks, we found increased connectivity of the bilateral opercular part of the inferior frontal gyrus (Brodmann area 44) in the SN. In SMN, there was increased connectivity in the right premotor cortex and decreased activity in the left visual cortex. Several areas showed increased (left primary auditory, secondary somatosensory, premotor and visual cortices, and left superior longitudinal fascicle) and decreased (right cerebellum and left frontal lobe) connectivity in DMN. We found no resting-state network changes after VIP.

\section{Conclusion}

The early phases of PACAP38-induced migraine attacks are associated with altered connectivity of several largescale functional networks of the brain.

\section{Authors' details}

'Danish Headache Center, Glostrup Hospital, Glostrup, Denmark. ${ }^{2}$ Department of Neurology, University Hospital Basel, Basel, Switzerland.

${ }^{3}$ Functional Imaging Unit, Glostrup Hospital, Glostrup, Denmark.

Published: 18 September 2014

doi:10.1186/1129-2377-15-S1-K1

Cite this article as: Amin et al:: EHMTI-0393. Abnormal ictal large-scale network connectivity in migraine without aura: a resting-state functional connectivity study. The Journal of Headache and Pain 2014 15(Suppl 1):K1.

Submit your manuscript to a SpringerOpen ${ }^{\odot}$ journal and benefit from:

- Convenient online submission

- Rigorous peer review

- Immediate publication on acceptance

- Open access: articles freely available online

- High visibility within the field

- Retaining the copyright to your article 